Summary: Two polythiophenes, containing either one (PTT) or two (PBTT) 2,5,8-trioxanonyl side chains per repeating unit, were synthesized with the objective of developing hybrid inorganic/organic semiconductor systems. From absorption and fluorescence spectroscopy and cyclic voltammetry it appears that introduction of a second 2,5,8trioxanonyl side chain on a repeating unit leads to a very short conjugation length. Atomic Force Microscopy (AFM) performed on composites of the two polythiophenes and a ZnSe single crystal reveals excellent wetting of the crystal by the polymers, leading to the formation of thin films. For the PTT/ZnSe composite, good contact between the constituents is substantiated by a red-shift of the PTT absorption relative to that of PTT on quartz. Fluorescence measurements indicate the occurrence of energy transfer from $\mathrm{ZnSe}$ to PTT, which might imply that there is electronic contact between $\mathrm{ZnSe}$ and PTT. Because of its highly distorted backbone, neither a significant red-shift compared with a film on quartz nor excitation energy transfer was found for the thin film of PBTT deposited on $\mathrm{ZnSe}$. Nevertheless, it is shown that the presence of polar 2,5,8-trioxanonyl side chains guarantees strong binding of polythiophenes to the $\mathrm{ZnSe}$ surface.

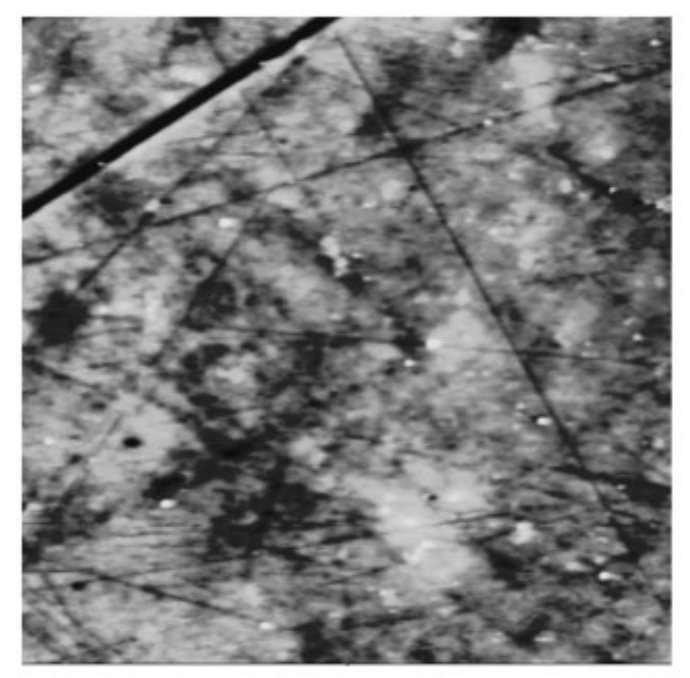

AFM contact mode topographical image of a PBTT film cast onto a ZnSe single crystal.

\title{
Polythiophenes Containing Oligo(oxyethylene) Side Chains as a Thin Film on a ZnSe Single Crystal Surface $^{\mathrm{a}}$
}

\author{
Rick van Beek, ${ }^{1}$ Leonardus W. Jenneskens, ${ }^{1}$ Aneliya N. Zdravkova, ${ }^{2}$ Jan P. J. M. van der Eerden, ${ }^{2}$ Cornelis A. van Walree ${ }^{* 1}$ \\ ${ }^{1}$ Debye Institute, Organic Chemistry and Catalysis, Utrecht University, Padualaan 8, 3584 CH Utrecht, The Netherlands \\ Fax: +31 302534533; E-mail: c.a.vanwalree@chem.uu.nl \\ ${ }^{2}$ Debye Institute, Department of Condensed Matter and Interfaces, Utrecht University, Princetonplein 1, 3584 CC Utrecht, \\ The Netherlands
}

Received: February 3, 2005; Revised: March 18, 2005; Accepted: March 21, 2005; DOI: 10.1002/macp.200500055

Keywords: atomic force microscopy (AFM); conducting polymers; excitation energy transfer; inorganic semiconductors

\section{Introduction}

The combination of inorganic and organic components in the design of functional materials is expected to lead to novel attractive properties which are absent in the separate components. An example of a field in which hybrid

\footnotetext{
a $\square$ Supporting information for this article is available at the bottom of the article's abstract page, which can be accessed from the journal's homepage at http://www.mcp-journal.de, or from the author.
}

inorganic/organic materials may be of interest is that of electroluminescence. Although organic semiconductors are useful as light-emitting diodes (LEDs) ${ }^{[1-4]}$ because of high quantum efficiencies, ease of processing, low costs and flexibility of the electroluminescent device, ${ }^{[5-10]}$ hybrid inorganic/organic systems can provide even more advantages. ${ }^{[11-13]}$ Recombination of charge carriers generated in the n-type inorganic material and in the p-type polymer may lead to intensive and tuneable emission. To obtain a functional hybrid inorganic/organic semiconductor system, an efficient electronic contact between the 


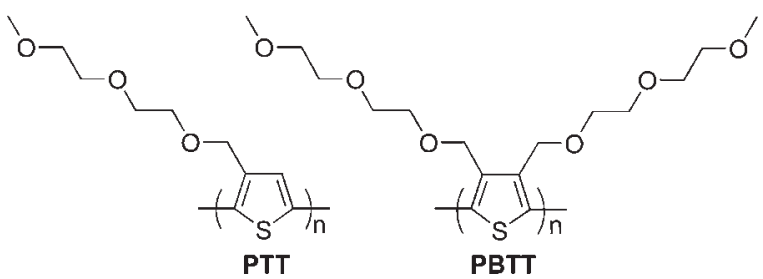

Scheme 1. Structures of PTT and PBTT.

inorganic part and the organic part is a prerequisite. This can be achieved by the use of polymers with side chains that possess a high affinity for inorganic materials.

As oligo(oxyethylene) chains are known to bind to polar inorganic species, it is expected that conducting polymers with oligo(oxyethylene) side chains are suitable candidates for application in hybrid organic/inorganic systems. Therefore, we investigated whether two polythiophenes, poly[3-(2,5,8-trioxanonyl)thiophene] (PTT, Scheme 1$)^{[14-17]}$ and poly[3,4-bis(2,5,8-trioxanonyl)thiophene] (PBTT, Scheme 1), exhibit an adhesive interaction with an inorganic semiconductor. The presence of the second 2,5,8-trioxanonyl side chain on the repeating unit of PBTT is expected to lead to improved contact between the polymer and the inorganic material as compared to the polythiophene with one side chain. However, it can also influence the electronic properties of the polythiophene, since increased steric repulsion between the side chains usually affects the backbone structure. ${ }^{[8]}$

In the target polymers, a methylene group is inserted between the thiophene ring and the first oxygen atom of the side chain in order to electronically decouple the oxygen lone pairs from the polythiophene backbone. This is expected to result in a relatively high oxidation potential of the polythiophene. This may be of interest since it facilitates hole injection into the valence band of an n-type inorganic material in a composite inorganic/organic system. For the same reason, $\mathrm{ZnSe}$ is used as the inorganic component since its oxidation potential ( $0.0-0.9 \mathrm{~V}$ vs. SCE in water, depending on $\mathrm{pH}$ ) is low compared with most other inorganic semiconductors. ${ }^{[18]}$ Thus, in this paper, the behavior of PTT and PBTT deposited onto single crystalline $\mathrm{ZnSe}$ has been studied. Atomic Force Microscopy (AFM) and absorption and fluorescence measurements on layers of the two polythiophenes on $\mathrm{ZnSe}$ were carried out. In addition, the photophysical properties, both in solution and after deposition on a quartz substrate, as well as the redox behavior of PTT and PBTT, are reported here.

\section{Experimental Part}

General

All syntheses were carried out in a nitrogen atmosphere. Prior to use, diethyl ether and THF were distilled from sodium/ benzophenone ketyl radical while chloroform was distilled from $\mathrm{CaCl}_{2}$. NMR spectra were recorded on a Bruker $\mathrm{AC}$ 300 spectrometer $\left({ }^{1} \mathrm{H} 300.133 \mathrm{MHz} ;{ }^{13} \mathrm{C} 75.47 \mathrm{MHz}\right)$ in $\mathrm{CDCl}_{3}$. Chemical shifts (ppm) are given downfield from TMS. IR spectra were recorded on a Mattson Galaxy Series FTIR 5000 spectrometer in diffuse reflectance mode. Samples were diluted with optically pure $\mathrm{KBr}$. Analytical size exclusion chromatography (SEC) was performed with a Jordi Gel DVB Mixed Bed column equipped with a Thermo Separation Product Series 200 pump and a UV-vis detector $(\lambda=440 \mathrm{~nm}$ for PTT, $\lambda=400 \mathrm{~nm}$ for poly(3-decylthiophene) and $\lambda=325 \mathrm{~nm}$ for PBTT).

Solution UV-vis absorption spectra were recorded on a Cary $1 \mathrm{UV}$-vis spectrophotometer, while solid-state UV-vis absorption spectra were obtained with a Cary 5 UV-vis-NIR spectrophotometer. Fluorescence spectra were taken on a Spex Fluorolog 2 apparatus. Films on quartz substrates for spectroscopic measurements were prepared by drop casting the polymer from a dichloromethane solution. Films on $\mathrm{ZnSe}$ single crystals were made by drop casting the polymer from a dichloromethane solution onto a $\mathrm{ZnSe}$ single crystal of $5 \times 5 \times 0.5 \mathrm{~mm}$, which was thoroughly rinsed with dichloromethane before use. Film thicknesses are estimated to be of the order of a few tens of $\mathrm{nm}$. For spectroscopic measurements, the crystal was glued onto a quartz plate. UV-vis spectra of the films on quartz were taken in transmission mode. For films on $\mathrm{ZnSe}$, a reflectance technique was used. Reflectance values, $R$, were subsequently converted into Kubelka-Munk data $F(R)$ by $F(R)=(1-R)^{2} / 2 R$. Fluorescence spectra of films were recorded using the front face geometry.

Cyclic voltammetry on PTT and PBTT was performed in THF solution. A $0.1 \mathrm{M}$ solution of tetrabutylammonium hexafluorophosphate was used as the electrolyte and an $\mathrm{Ag}$ / $\mathrm{AgCl}$ reference electrode was used. The electrodes were prepared as described in the literature. ${ }^{[19]} \mathrm{AFM}$ was carried out using a Digital Instrument Nanoscope (R) III instrument equipped with an $\mathrm{E}$ scanner in contact mode with an oxidesharpened silicon nitride tip $\left(k=0.12 \mathrm{~N} \cdot \mathrm{m}^{-1}\right)$. The PTT and PBTT samples were obtained by drop casting $20 \mu \mathrm{L}$ of a $5.0 \times 10^{-5}$ M polymer solution in dichloromethane onto a $\mathrm{ZnSe}$ single crystal. To obtain a sample from the not completely soluble poly(3-decylthiophene), the polymer was drop cast from $20 \mu \mathrm{L}$ of a polymer solution in dichloromethane having the same absorbance as PTT. It was assumed that the absorption coefficients at the absorption maximum of PTT $(440 \mathrm{~nm})$ and poly(3-decylthiophene) $(436 \mathrm{~nm})$ had similar values.

\section{Synthesis}

\section{Poly[3-(2,5,8-trioxanonyl)thiophene] (PTT)}

PTT was prepared using a method developed by McCullough and Williams. ${ }^{[14]}$ The crude product was washed with hexane in a soxhlet apparatus. Then, the residue was consecutively soxhlet extracted with methanol and chloroform. The methanol extract was evaporated in vacuo and the residue was precipitated from chloroform into methanol/water (4:1). A red solid $\left(0.39 \mathrm{~g}, 9 \%, \bar{M}_{\mathrm{w}}=1.7 \times 10^{4}, D=2.2\right)$ was obtained, which was used in all the experiments described in this paper. 
The chloroform extract was washed with water and evaporated in vacuo, which yielded $0.25 \mathrm{~g}(6 \%)$ of a red solid $\left(\bar{M}_{\mathrm{w}}=2.3 \times 10^{4}, D=2.0\right)$. The product was soluble in chloroform, dichloromethane, THF and toluene, whereas it was sparingly soluble in methanol and insoluble in water and hexane.

${ }^{1} \mathrm{H}$ NMR (both the methanol and the chloroform extract) $\left(\mathrm{CDCl}_{3}\right): \delta=7.25(\mathrm{~s}, 1 \mathrm{H}$, aromatic $\mathrm{H}), 4.67\left(\mathrm{~s}, 2 \mathrm{H}, \mathrm{CH}_{2} \alpha\right.$ to the thiophene ring), $3.74(\mathrm{~m}, 4 \mathrm{H}), 3.71-3.67(\mathrm{~m}, 2 \mathrm{H}), 3.58-3.55$ $(\mathrm{m}, 2 \mathrm{H}), 3.37\left(\mathrm{~s}, 3 \mathrm{H}, \mathrm{OCH}_{3}\right)$.

${ }^{13} \mathrm{C} \mathrm{NMR}\left(\mathrm{CDCl}_{3}\right): \delta=136.4,134,5,133.3,129.8,72.2$, $70.8(2 \times), 69.9,67.1,59.2$.

FT-IR: 3 065, 2 868, 1 726, 1 456, 1 352, 1 286, 1 246, 1 198, $1105,1026,844 \mathrm{~cm}^{-1}$.

\section{3,4-Dimethylthiophene 4}

A solution of methyl iodide $(22.71 \mathrm{~g}, 160 \mathrm{mmol})$ in diethyl ether $(40 \mathrm{~mL})$ was added dropwise over $30 \mathrm{~min}$ to $\mathrm{Mg}$ turnings (5.33 g, $219 \mathrm{mmol})$, which had been activated with 1,2dibromoethane, and the mixture was heated at reflux temperature for $2 \mathrm{~h}$. The solution was added dropwise, while cooling with ice, to a solution of 3,4-dibromothiophene $\mathbf{3}^{\text {[20] }}$ $(15.65 \mathrm{~g}, 64.7 \mathrm{mmol})$ and $\mathrm{Ni}(\mathrm{dppp}) \mathrm{Cl}_{2}(0.70 \mathrm{~g}, 1.36 \mathrm{mmol})$ in diethyl ether $(650 \mathrm{~mL})$. The reaction mixture was heated at reflux temperature overnight and then poured into $1 \mathrm{M} \mathrm{HCl}$ $(600 \mathrm{~mL})$. The layers were separated and the aqueous layer was extracted with diethyl ether $(3 \times 300 \mathrm{~mL})$. The combined ethereal layers were washed with saturated $\mathrm{NaHCO}_{3}$ solution $(1 \times 600 \mathrm{~mL})$ and water $(1 \times 600 \mathrm{~mL})$, dried $\left(\mathrm{MgSO}_{4}\right)$ and filtered. The filtrate was concentrated in vacuo, yielding $2.08 \mathrm{~g}$ ( $18.5 \mathrm{mmol}, 80 \%)$ of a brownish liquid.

${ }^{1} \mathrm{H} \mathrm{NMR}\left(\mathrm{CDCl}_{3}\right): \delta=6.85(\mathrm{~s}, 2 \mathrm{H}$, aromatic $\mathrm{H}), 2.15(\mathrm{~s}, 6 \mathrm{H}$, $\mathrm{CH}_{3}$ ).

${ }^{13} \mathrm{C}$ NMR $\left(\mathrm{CDCl}_{3}\right): \delta=137.3,120.7,14.4$.

\section{2,5-Dibromo-3,4-bis(bromomethyl)thiophene 5}

To a boiling suspension of 4 (2.70 g, $24.1 \mathrm{mmol})$ and benzoyl peroxide $(71.3 \mathrm{mg}, 0.29 \mathrm{mmol})$ in $\mathrm{CCl}_{4}(35 \mathrm{~mL})$ was added a mixture of $N$-bromosuccinimide (NBS) $(8.67 \mathrm{~g}, 48.7 \mathrm{mmol})$ and benzoyl peroxide ( $99 \mathrm{mg}, 0.41 \mathrm{mmol}$ ). The mixture was kept at reflux temperature for $3 \mathrm{~d}$. To complete bromination of the methyl groups, additional aliquots of NBS (in total $10.89 \mathrm{~g}$, $61.2 \mathrm{mmol}$ ) and benzoyl peroxide (in total $270 \mathrm{mg}, 1.11 \mathrm{mmol}$ ) were added in three parts. The succinimide formed was removed by filtration. The filtrate was washed with $2 \mathrm{M} \mathrm{NaOH}$ $(3 \times 200 \mathrm{~mL})$, dried $\left(\mathrm{MgSO}_{4}\right)$ and filtered. This was followed by removal of the solvent in vacuo. Recrystallization from ethyl acetate yielded $\mathbf{5}(5.14 \mathrm{~g}, 12.0 \mathrm{mmol}, 50 \%)$ as pale brown crystals.

${ }^{1} \mathrm{H} \mathrm{NMR}\left(\mathrm{CDCl}_{3}\right): \delta=4.54\left(\mathrm{~s}, 4 \mathrm{H}, \mathrm{CH}_{2}\right)$.

${ }^{13} \mathrm{C} \mathrm{NMR}\left(\mathrm{CDCl}_{3}\right): \delta=136.0,114.0,23.7$.

\section{2,5-Dibromo-3,4-bis(2,5,8-trioxanonyl)thiophene 6}

The synthesis of $\mathbf{6}$ was carried out according to a slightly modified literature procedure. ${ }^{[14]}$ 2-(2-Methoxyethoxy)ethanol (5.61 g, $46.7 \mathrm{mmol})$ (dried on $4 \AA$ molecular sieves) was added dropwise to a suspension of $\mathrm{NaH}(1.67 \mathrm{~g}$ of a $60 \%$ suspension in mineral oil, $41.8 \mathrm{mmol} \mathrm{NaH})$ in THF (25 mL). After stirring overnight, a solution of $5(4.98 \mathrm{~g}, 11.9 \mathrm{mmol})$ in THF $(75 \mathrm{~mL})$ was added dropwise to the brown solution. The solvent was removed in vacuo and diethyl ether $(350 \mathrm{~mL})$ and water $(350 \mathrm{~mL})$ were added to the residue. The layers were separated upon which the water layer was extracted with diethyl ether $(2 \times 350 \mathrm{~mL})$. The combined ethereal extracts were washed with water $(3 \times 400 \mathrm{~mL})$, dried $\left(\mathrm{MgSO}_{4}\right)$ and filtered. After concentration of the filtrate in vacuo, the product was purified with column chromatography on silica gel using chloroform/acetone (10:1) as the eluent. A yellow oil (4.71 g, $9.3 \mathrm{mmol}, 80 \%$ ) was obtained.

${ }^{1} \mathrm{H} \mathrm{NMR}\left(\mathrm{CDCl}_{3}\right): \delta=4.58$ (s, $4 \mathrm{H}, \mathrm{CH}_{2} \alpha$ to thiophene ring), $3.64-3.60\left(\mathrm{~m}, 12 \mathrm{H}, \mathrm{OCH}_{2}\right), 3.55-3.53\left(\mathrm{~m}, 4 \mathrm{H}, \mathrm{OCH}_{2}\right), 3.37$ $\left(\mathrm{s}, 6 \mathrm{H}, \mathrm{OCH}_{3}\right)$.

${ }^{13} \mathrm{C} \mathrm{NMR}\left(\mathrm{CDCl}_{3}\right): \delta=137.6,112.7,71.8,70.4,70.3,69.3$, 65.1, 58.9.

FT-IR: 2 900, 1454, 1 350, 1 200, 1 144, 1 107, 1 030, 981, $937,851 \mathrm{~cm}^{-1}$.

\section{Poly[3,4-bis(2,5,8-trioxanonyl)thiophene] (PBTT)}

A mixture of 6 (2.28 g, $4.5 \mathrm{mmol})$, bis-(1,5-cyclooctadiene)nickel $(2.07 \mathrm{~g}, 7.8 \mathrm{mmol})$, cyclooctadiene $(0.57 \mathrm{~g}, 5.3 \mathrm{mmol})$ and triphenylphosphine $(1.53 \mathrm{~g}, 5.8 \mathrm{mmol})$ in DMF $(60 \mathrm{~mL})$ was stirred overnight at $70^{\circ} \mathrm{C}$. The reaction mixture was poured into $1 \mathrm{M} \mathrm{HCl}(250 \mathrm{~mL})$ and extracted with dichloromethane $(3 \times 150 \mathrm{~mL})$. The combined organic layers were washed with water $(2 \times 150 \mathrm{~mL})$, dried $\left(\mathrm{MgSO}_{4}\right)$, filtered and evaporated. The residue was precipitated from dichloromethane $(20 \mathrm{~mL})$ into hexane $(400 \mathrm{~mL})$. The precipitate was reprecipitated from chloroform $(15 \mathrm{~mL})$ into diethyl ether $(300 \mathrm{~mL})$. The supernatant was evaporated, subjected to preparative SEC (Bio-Beads SX-1) and twice precipitated from chloroform $(5 \mathrm{~mL})$ into hexane $(60 \mathrm{~mL})$. The yield was $0.64 \mathrm{~g}$ (41\%) of a yellow oil $\left(\bar{M}_{\mathrm{w}}=2.1 \times 10^{4}, D=2.7\right)$. The product was soluble in chloroform, dichloromethane, THF, toluene, methanol and water, but insoluble in hexane.

${ }^{1} \mathrm{HNMR}\left(\mathrm{CDCl}_{3}\right): \delta=4.59$ (s, $4 \mathrm{H}, \mathrm{CH}_{2} \alpha$ to thiophene ring), 3.66-3.61 (m, 12H), 3.54-3.51 (m, 4H), $3.35\left(\mathrm{~s}, 6 \mathrm{H}, \mathrm{OCH}_{3}\right)$.

${ }^{13} \mathrm{C} \mathrm{NMR}\left(\mathrm{CDCl}_{3}\right): \delta=138.4,133.2,71.9,70.4(2 \times), 69.9$, $65.5,59.0$.

FT-IR: 2 874, 1 724, 1 452, 1 348, 1 200, 1 107, 1 028, 885, $850 \mathrm{~cm}^{-1}$.

\section{Poly(3-decylthiophene)}

This polymer was prepared from 3-decylthiophene using iron trichloride as described by Jin et al. ${ }^{[21]}$ A dark solid (61\% yield) with $\bar{M}_{\mathrm{w}}=9.7 \times 10^{4}$ and $D=4.4$ was obtained.

${ }^{1} \mathrm{H} \mathrm{NMR}\left(\mathrm{CDCl}_{3}\right): \delta=6.97(\mathrm{~s}, 1 \mathrm{H}$, aromatic $\mathrm{H}), 2.80(\mathrm{t}$, $1.5 \mathrm{H}, \mathrm{CH}_{2} \alpha$ to thiophene ring), $2.55\left(\mathrm{t}, 0.5 \mathrm{H}, \mathrm{CH}_{2} \alpha\right.$ to thiophene ring), $1.85\left(\mathrm{~m}, 2 \mathrm{H}, \mathrm{CH}_{2}\right), 1.27\left(\mathrm{~m}, 14 \mathrm{H}, 7 \times \mathrm{CH}_{2}\right)$, $0.87\left(\mathrm{t}, 3 \mathrm{H}, \mathrm{CH}_{3}\right)$.

${ }^{13} \mathrm{C} \mathrm{NMR}\left(\mathrm{CDCl}_{3}\right): \delta=139.9,133.7,130.5,128.6,31.9$, 30.6, 29.7, 29.6, 29.5, 29.4, 22.7, 14.1 .

FT-IR: 3 055, 2921, 2 852, 1 639, 1 457, 1377,1 180, 824, $720,666 \mathrm{~cm}^{-1}$. 


\section{3,4-Bis(2,5,8-trioxanonyl)thiophene}

Butyllithium (2.5 mL of a $1.6 \mathrm{~m}$ solution in hexanes, $4.0 \mathrm{mmol})$ was added using a syringe to a solution of $6(1.01 \mathrm{~g}, 2.0 \mathrm{mmol})$ in diethyl ether $(40 \mathrm{~mL})$ at $-60^{\circ} \mathrm{C}$. The reaction mixture was stirred at that temperature for $4 \mathrm{~h}$. To complete the conversion of 6, additional aliquots of butyllithium (in total $2.5 \mathrm{~mL}$ of a $1.6 \mathrm{~m}$ solution in hexane) were added in four parts. The reaction mixture was poured into ice water $(60 \mathrm{~mL})$. After extraction with diethyl ether $(4 \times 75 \mathrm{~mL})$, the combined ethereal layers were dried $\left(\mathrm{MgSO}_{4}\right)$ and filtered. This was followed by concentration of the filtrate in vacuo. The yield was $0.42 \mathrm{~g}$ $(1.2 \mathrm{mmol}, 60 \%)$ of a yellow oil.

${ }^{1} \mathrm{H} \mathrm{NMR}\left(\mathrm{CDCl}_{3}\right): \delta=7.22(\mathrm{~s}, 2 \mathrm{H}$, aromatic $\mathrm{H}), 4.56(\mathrm{~s}, 4 \mathrm{H}$, $\mathrm{CH}_{2} \alpha$ to thiophene ring), 3.68-3.62 (m, $\left.12 \mathrm{H}, \mathrm{OCH}_{2}\right), 3.58-$ $3.54\left(\mathrm{~m}, 4 \mathrm{H}, \mathrm{OCH}_{2}\right), 3.37\left(\mathrm{~s}, 6 \mathrm{H}, \mathrm{OCH}_{3}\right)$.

${ }^{13} \mathrm{C} \mathrm{NMR}\left(\mathrm{CDCl}_{3}\right): \delta=137.7,124.1,71.8,70.5,70.4,69.3$, $67.4,58.8$

\section{Results and Discussion}

\section{Synthesis}

Regioregular poly[3-(2,5,8-trioxanonyl)thiophene] (PTT) was prepared by firstly converting 2-bromo-3-(bromomethyl)thiophene $\mathbf{1}^{[22]}$ into the trioxanonyl-functionalized monomer 2 by etherification with the sodium salt of 2 (2-methoxyethoxy)ethanol (Scheme 2). Monomer 2 was polymerized using a method developed by McCullough and Williams. ${ }^{[14]} \mathrm{A} \mathrm{MgBr}$ substituent was introduced at the 5position of the thiophene ring, followed by a $\mathrm{Ni}(\mathrm{dppp}) \mathrm{Cl}_{2^{-}}$ catalyzed polymerization. ${ }^{\mathrm{b}}$ The polymerization gave material with a weight-average molecular weight, $\bar{M}_{\mathrm{w}}$, of $1.7 \times 10^{4}$ and a polydispersity, $D$, of 2.2 , as determined by size exclusion chromatography (SEC). According to its ${ }^{1} \mathrm{H}$ NMR and ${ }^{13} \mathrm{C}$ NMR spectra, the obtained product was highly regioregular. ${ }^{[23]}$

To obtain the 3,4-disubstituted polythiophene PBTT, 3,4dibromothiophene $\mathbf{3}^{[20]}$ was subjected to a reaction with methyl magnesium iodide to yield 3,4-dimethylthiophene 4 (Scheme 3). Tetrabromide 5 was obtained by reaction of 4 with NBS in the presence of benzoyl peroxide. This resulted in radical bromination of the two methyl groups as well as electrophilic aromatic substitution at the 2- and 5positions of the thiophene ring. Etherification of the bromomethyl groups of $\mathbf{5}$ with the sodium salt of 2-(2methoxyethoxy)ethanol gave the bis(2,5,8-trioxanonyl) compound 6, which was polymerized using $\mathrm{Ni}(\operatorname{cod})_{2} \cdot{ }^{[24]}$ This gave material with $\bar{M}_{\mathrm{w}}=2.1 \times 10^{4}$ and $D=2.7$.

\section{Photophysical Studies}

To study the effect of the introduction of two 2,5,8trioxanonyl side chains on a repeating unit, UV-vis absorp-

\footnotetext{
b Attempts were also made to synthesize PTT from 3-(2,5,8trioxanonyl)thiophene using iron trichloride. However, this synthesis yielded only insoluble material.
}

tion spectra of PTT and PBTT were recorded, both in chloroform solution and as a film on quartz (see Figure 1). The absorption maximum $\left(\lambda_{\max }\right)$ of PTT in chloroform $(440 \mathrm{~nm})$ agrees well with that reported by McCullough and Williams. ${ }^{[14,15]}$ The spectrum resembles that of polythiophenes containing alkyl side chains of a similar length, like octyl and decyl. ${ }^{[23]}$ Attachment of a second 2,5,8trioxanonyl side chain on a monomer unit induces a strong hypsochromic shift of $8040 \mathrm{~cm}^{-1}$, to $325 \mathrm{~nm}$. This indicates a marked degree of twisting of the backbone for PBTT, which must be caused by steric repulsion between side chains on adjacent units. The blue-shift is very large in comparison with that found for other 3,4-disubstituted polythiophenes. For example, the blue-shift observed for poly(3,4-dibutoxythiophene) relative to poly(3-butoxythiophene) amounts to $1970 \mathrm{~cm}^{-1} \cdot[8,25]$

The UV-vis absorption spectrum of PTT after deposition as a film on quartz is red-shifted $\left(\lambda_{\max }=485 \mathrm{~nm}\right)$ and broadened as compared to the spectrum taken in chloroform solution. This red-shift is a well-known phenomenon which shows that in the solid state the polymer chains are in a more ordered conformation than the random coil conformation present in solution. The broadening of the UV-vis absorption spectrum of PTT in the solid state as compared to that in solution is attributed to a larger heterogeneity in conjugation length in the solid state. In contrast, the UV-vis absorption spectrum of PBTT is not affected by going from chloroform solution to the solid state (film on quartz). Apparently, PBTT cannot adopt a more ordered conformation in the solid state because there is too much steric repulsion between the side chains. The behavior of PTT and PBTT agreed well with that found earlier by Li et al. ${ }^{[8]}$ They reported that for poly(3-hexylthiophene) there is a red-shift of $4440 \mathrm{~cm}^{-1}$ when going from solution to the solid state, whereas it is only a few hundred $\mathrm{cm}^{-1}$ for a series of poly(3hexylthiophene)s with a 4-substituent. For PBTT the situation is actually very extreme, as this polymer does not show any red-shift at all.

The fluorescence spectra of PTT and PBTT (Figure 2) show similar trends to those found in the UV-vis absorption spectra. For PTT, the emission maximum shifts from $570 \mathrm{~nm}$ in chloroform to $630 \mathrm{~nm}$ in the solid state. This redshift $\left(1670 \mathrm{~cm}^{-1}\right)$ is slightly smaller than the red shift in the absorption maxima $\left(2070 \mathrm{~cm}^{-1}\right.$, see Figure 1$)$. The emission maximum of PBTT $(450 \mathrm{~nm})$ is not affected on going from chloroform solution to the solid state, as is the case for the absorption maximum. The only difference is that the emission spectrum of the film on quartz is somewhat broader, particularly at the red side. Apparently, in the solid state, more segments of relatively long conjugation lengths emit radiation than in chloroform solution. This can be explained by the occurrence of interchain energy transfer, which is only possible in the solid state. The behavior of PBTT is in line with the emission maxima found for poly(3-hexylthiophenes) with another substituent at the 


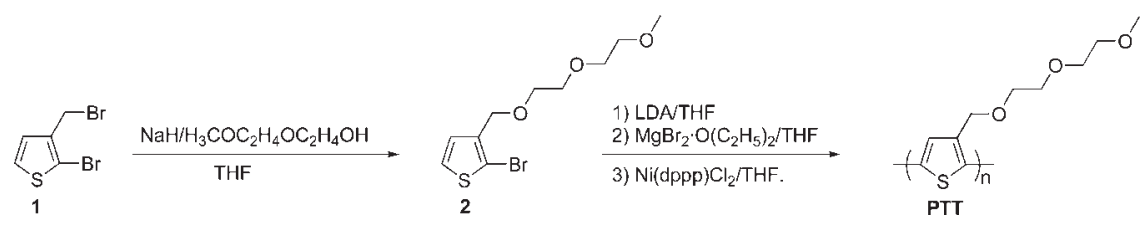

Scheme 2. Synthetic route to PTT.

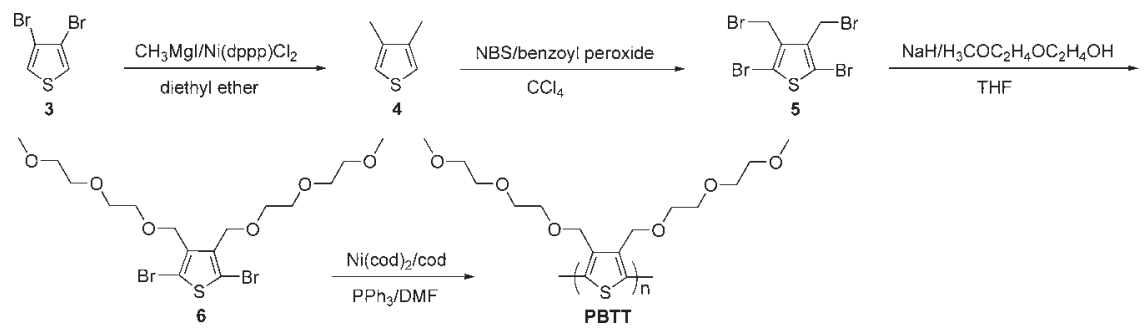

Scheme 3. Synthetic route to PBTT.

4-position. The emission maxima of these polythiophenes also did not change upon going from solution to the solid state. $^{[8] \mathrm{c}}$ The fluorescence excitation spectra of PTT and PBTT (upon monitoring the emission maximum) are slightly red-shifted $(10-20 \mathrm{~nm})$ compared to the UV-vis absorption spectra, both in chloroform solution and in the solid state. This indicates that in the fluorescence process longer chain segments are involved than those responsible for the UV-vis absorption spectra.

\section{Cyclic Voltammetry}

Figure 3 shows a cyclic voltammogram of a 0.01 m solution of PTT in THF. In the voltammogram three oxidation waves can be seen. The weak signals centered around 0.6 and $1.0 \mathrm{~V}$ vs. $\mathrm{Ag} / \mathrm{AgCl}$ can be assigned to the electrolyte solution, ${ }^{\mathrm{d}}$ since those signals were also found in blank samples. The quasi-reversible signal centered at $0.7 \mathrm{~V}$ vs. $\mathrm{Ag} / \mathrm{AgCl}$ represents the first oxidation process of PTT. It is situated at a somewhat higher value than the first oxidation signal found for a PTT film deposited on a Pt disk electrode, measured in acetonitrile $\left(0.59 \mathrm{~V}\right.$ vs. $\left.\mathrm{SCE}^{[15]}\right)$. Although it is difficult to compare data obtained in the solid state and in solution (and in different solvents), this may reflect the conformational disorder of PTT in solution compared with PTT in the solid state (c.f. Figure 1). The decoupling of the oxygen lone pairs from the polythiophene backbone becomes apparent when

${ }^{c}$ In some other cases introduction of a second substituent on a repeating unit resulted in a limited red-shift (ca. $10 \mathrm{~nm}$ ) of the emission maximum, indicating that a small change in emission maximum is possible. See also ref. ${ }^{[8]}$

d The reduction potential of $\mathrm{Ag} / \mathrm{AgCl}$ is $0.02 \mathrm{~V}$ higher than that of $\mathrm{SCE}$. Therefore, in practice the $\mathrm{CV}$ potentials vs. $\mathrm{Ag} / \mathrm{AgCl}$ also refer to SCE as the reference electrode. the oxidation potential of PTT is compared with that of poly[3-oligo(oxyethylene)-4-methylthiophene], which is considerably lower $(0.2 \mathrm{~V}$ vs. SCE, measured as a film in acetonitrile). ${ }^{[26]}$ The oxidation potential determined from Figure 3 matches well with the oxidation potential of $\mathrm{ZnSe}$ $(0-0.9 \mathrm{~V}$ vs. SCE in water, depending on the $\mathrm{pH}) .^{[18]}$ Although these data were obtained under different conditions, they suggest that hole injection from PTT into ZnSe will be feasible. Thus, according to the redox potentials, PTT and ZnSe form a suitable hybrid inorganic/organic system for potential application in LEDs.

Cyclic voltammetry was also performed on a solution of PBTT in THF. However, no oxidation waves belonging to the polymer could be detected within the available potential window ( $<1.2 \mathrm{~V}$ vs. $\mathrm{Ag} / \mathrm{AgCl})$. This is consistent with the presence of a highly distorted polythiophene backbone, as was deduced from the UV-vis absorption and the fluorescence spectra. An upper limit to the oxidation potential of

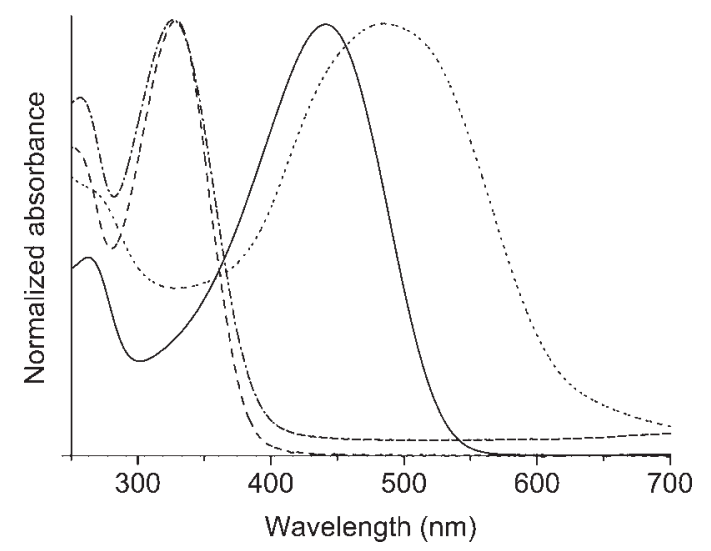

Figure 1. UV-vis absorption spectra of PTT in chloroform solution (solid line), PBTT in chloroform solution (dashed line), PTT as a film on quartz (dotted line) and PBTT as a film on quartz (dash-dotted line). 


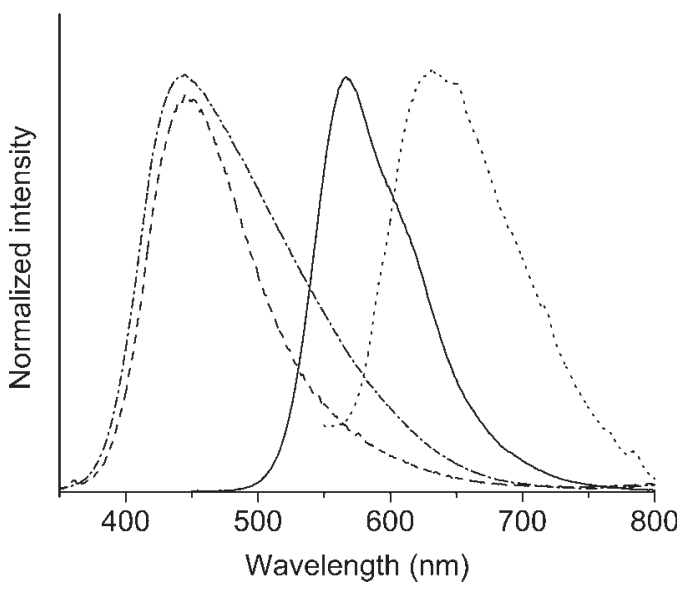

Figure 2. Fluorescence spectra of PTT in chloroform solution (solid line), PBTT in chloroform solution (dashed line), PTT as a film on quartz (dotted line) and PBTT as a film on quartz (dashdotted line).

PBTT can be obtained by considering the oxidation potential of monomeric 3,4-bis(2,5,8-trioxanonyl)thiophene, which was determined to be $2.0 \mathrm{~V}$ vs. $\mathrm{Ag} / \mathrm{AgCl}$. Probably, the oxidation potential of PBTT lies between 1.2 and $2.0 \mathrm{~V}$ vs. $\mathrm{Ag} / \mathrm{AgCl}$. In this respect, PBTT may be an even better candidate than PTT for use in a composite hybrid inorganic/ organic system with ZnSe.

\section{Polythiophene/ZnSe Single Crystal Composites}

In order to obtain an insight into the interaction between the two polythiophenes and single crystalline ZnSe, AFM images were taken of films of PTT and PBTT deposited on a $\mathrm{ZnSe}$ single crystal. These films were cast from dichloromethane solution. In Figure 4(a) and 4(c), the topographical AFM images of PTT and PBTT are shown. The straight dark lines in the images represent scratches in the ZnSe substrate (see Supporting Information, which contains an AFM image of a bare $\mathrm{ZnSe}$ single crystal).

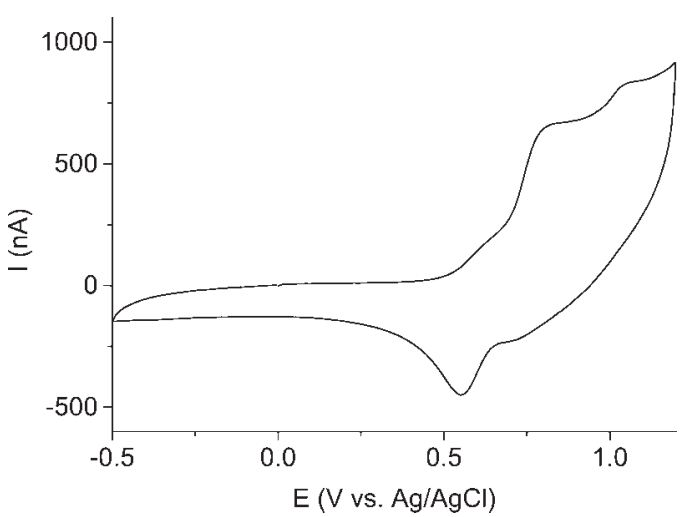

Figure 3. Cyclic voltammogram of a $0.01 \mathrm{~m}$ solution of PTT in THF.
Figure 4(a) and 4(c) make clear that the wettability of the ZnSe single crystal with PTT and PBTT is excellent. For both polythiophenes, the $\mathrm{ZnSe}$ surface is almost fully covered with a thin layer of quite uniform thickness. As determined from the cross sections taken from Figure 4(a) and 4 (c), the average thickness was ca. $4 \mathrm{~nm}$. The formation of thin films was confirmed by scratching a $0.5 \times 0.5 \mu \mathrm{m}$ square in the PTT film (see Figure 4(b)), which clearly reveals a thickness of ca. $4 \mathrm{~nm}$. Hence, the AFM results indicates good physical contact between the two polythiophenes and $\mathrm{ZnSe}$. To establish the role of the side chain, a film of poly(3-decylthiophene) deposited on a $\mathrm{ZnSe}$ single crystal was investigated as well (Figure 4(d)). In contrast to PTT and PBTT, the wettability of the ZnSe surface with poly(3-decylthiophene) is very poor. This polymer forms isolated, elongated domains having an average height of ca. $30 \mathrm{~nm}$. Thus, poly(3-decylthiophene) and $\mathrm{ZnSe}$ are essentially incompatible, which implies that the presence of polar 2,5,8-trioxanonyl side chains is essential to achieve an adhesive contact with semiconductors such as $\mathrm{ZnSe}$.

Figure 5 shows the Kubelka-Munk spectra of PTT and PBTT films cast from dichloromethane onto a $\mathrm{ZnSe} \mathrm{single}$ crystal, together with the spectrum of a bare ZnSe single crystal. The bare $\mathrm{ZnSe}$ single crystal has an absorption onset at $530 \mathrm{~nm}$. For the PTT/ZnSe system, the onset is situated at $620 \mathrm{~nm}$ because of the absorption of PTT. The absorption maximum of PTT on $\mathrm{ZnSe}(535 \mathrm{~nm})$ is clearly red-shifted $\left(1930 \mathrm{~cm}^{-1}\right)$ compared with a film on quartz $\left(\lambda_{\max }=485 \mathrm{~nm}\right)$. On ZnSe, longer chain segments appear to be involved in the absorption process. It is highly probable that this is the consequence of an interaction between the side chains of PTT and the ZnSe single crystal and it indicates that PTT is in a more ordered conformation than in the film on quartz. The absorption onset of the PBTT/ZnSe single crystal system is the same as for the bare $\mathrm{ZnSe}$ single crystal. The spectrum of PBTT is visible at short wavelengths, the maximum being situated at $330 \mathrm{~nm}$. This absorption maximum is only slightly bathochromically shifted compared with that of the PBTT film on quartz $\left(\lambda_{\max }=325 \mathrm{~nm}\right)$. Apparently, the conformation of the PBTT backbone does not change significantly upon casting onto a $\mathrm{ZnSe}$ single crystal surface.

Figure 6 shows the fluorescence emission spectrum of a PTT film on a ZnSe single crystal, together with the fluorescence emission spectra of a bare ZnSe single crystal and of a PTT film on quartz. The emission spectrum of the bare $\mathrm{ZnSe}$ single crystal (excited at $480 \mathrm{~nm}$ ) show a maximum at $600 \mathrm{~nm}$. As indicated by its short (picosecond) lifetime, ${ }^{[27-30]}$ this emission represents fluorescence. The emission spectra of the two other systems are red-shifted compared with that of $\mathrm{ZnSe}$ and both show a maximum near $630 \mathrm{~nm}$. This implies that upon excitation in the absorption band of the ZnSe single crystal ( $480 \mathrm{~nm}$ ), mainly the emission of PTT is observed. Although one should be 

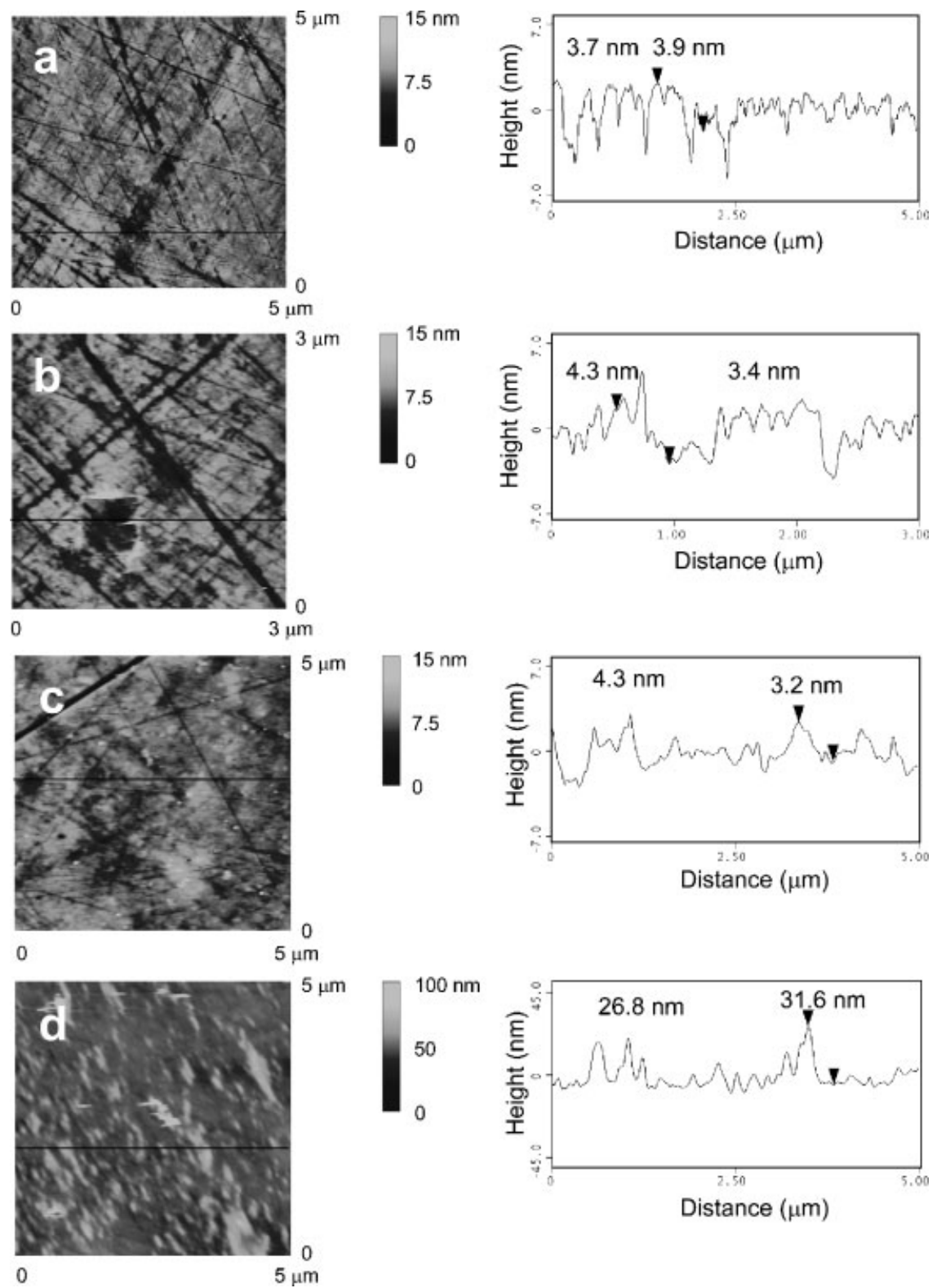

Figure 4. AFM contact mode topographical images $(5 \times 5 \mu \mathrm{m})$ and cross section profiles of polythiophene films cast onto a ZnSe single crystal: a) PTT; b) PTT after scratching a $0.5 \times 0.5 \mu \mathrm{m}$ square $(3 \times 3 \mu \mathrm{m}$ image); c) PBTT; d) poly(3-decylthiophene). The thickness of the layers is given by the vertical distance between the markers on the corresponding cross section profiles. Note the different height scale in (d).

aware of interference effects, ${ }^{[31]}$ this indicates that excitation energy transfer (EET) from the ZnSe single crystal to the polythiophene takes place. This is confirmed by the excitation spectra shown in Figure 7. The excitation spectrum of the ZnSe/PTT composite clearly shows that the occurrence of PTT emission is predominantly the result of excitation of the $\mathrm{ZnSe}$ single crystal. The EET revealed by Figure 6 and 7 can proceed via three different mechanisms: ${ }^{[32]}$ emission-reabsorption, dipole-dipole interaction (Förster mechanism) or electron exchange (Dexter mechanism). At this moment, it is not clear which mechanism is operating in the PTT/ZnSe system. If the Dexter mechanism proves to be operating, i.e., simultaneous electron and hole transfer between PTT and ZnSe occurs, there is real electronic contact between these constituents.

Another feature that emerges from Figure 6 is that the emission spectrum of PTT on ZnSe is significantly narrower than that of PTT on quartz, particularly at the blue side. As already revealed by Figure 5 , the backbone conformation of PTT on $\mathrm{ZnSe}$ is somewhat different from that of PTT on quartz. This results into a modified distribution of chain lengths that emit radiation. It can however not 


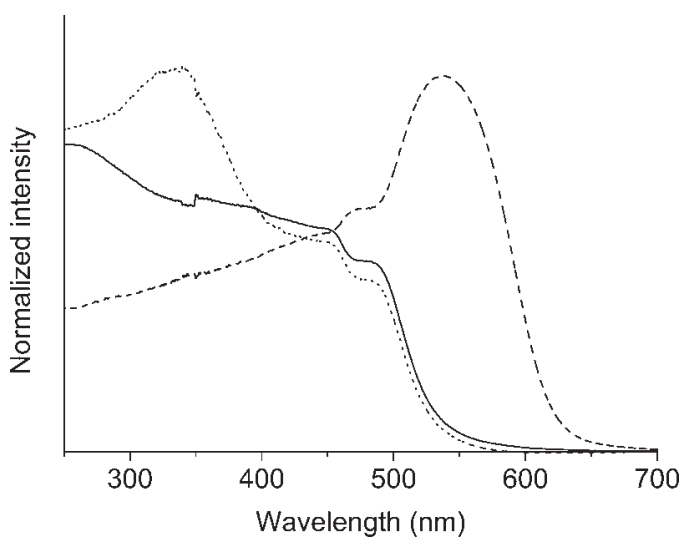

Figure 5. Kubelka-Munk absorption spectra of ZnSe single crystal (solid line), PTT as a film on ZnSe (dashed line) and PBTT as a film on $\mathrm{ZnSe}$ (dotted line).

be excluded that the narrowing of the emission band is the result of reabsorption of radiation emitted near $600 \mathrm{~nm}$ by PTT, or that interference phenomena contribute.

We also tried to reveal EET between a ZnSe single crystal and PBTT. In this case, EET from ZnSe to the polymer is not possible since the first excited state of PBTT lies much higher in energy than that of $\mathrm{ZnSe}$ (see Figure 5). Although there is favorable spectral overlap between the emission of PBTT $\left(\lambda_{\max }=455 \mathrm{~nm}\right)$ and the absorption of $\mathrm{ZnSe}$ $\left(\lambda_{\max }=480 \mathrm{~nm}\right)$, EET from PBTT to ZnSe could not be unambiguously established. When exciting in the absorption maximum of PBTT, mainly ZnSe emission $\left(\lambda_{\mathrm{em}, \max }=\right.$ $600 \mathrm{~nm}$ ) was observed, indicating that EET might occur. Unfortunately, this was not substantiated by the excitation spectrum taken while monitoring the $\mathrm{ZnSe}$ emission maximum, which did not reveal excitation of PBTT. This might be the consequence of the large absor-

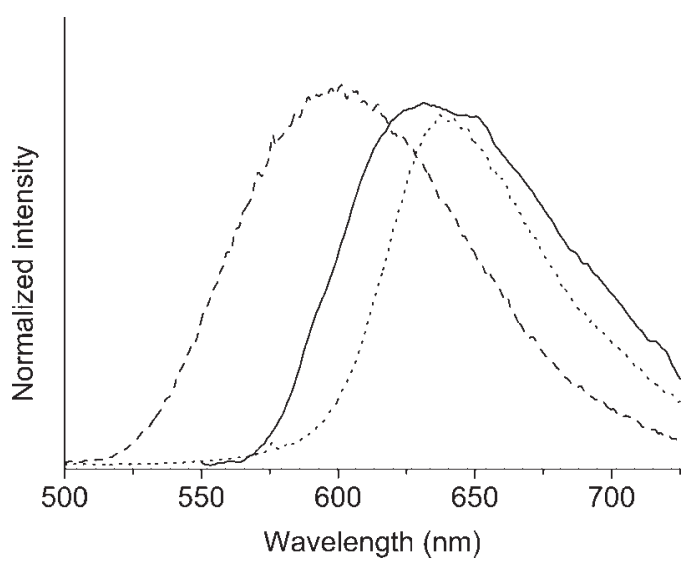

Figure 6. Fluorescence emission spectra of PTT as a film on quartz $\left(\lambda_{\mathrm{exc}}=494 \mathrm{~nm}\right.$, solid line $)$, ZnSe single crystal $\left(\lambda_{\mathrm{exc}}=\right.$ $480 \mathrm{~nm}$, dashed line) and PTT as a film on ZnSe single crystal $\left(\lambda_{\text {exc }}=480 \mathrm{~nm}\right.$, dotted line $)$.

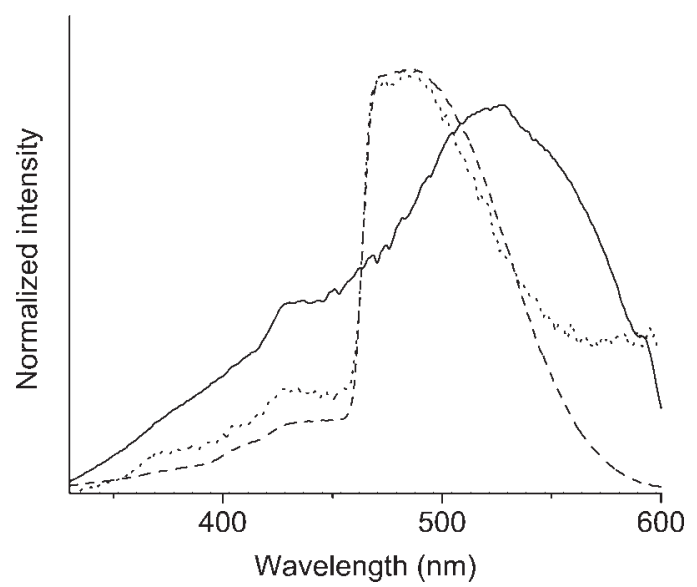

Figure 7. Fluorescence excitation spectra of PTT as a film on quartz $\left(\lambda_{\mathrm{em}}=650 \mathrm{~nm}\right.$, solid line), ZnSe single crystal $\left(\lambda_{\mathrm{em}}=625 \mathrm{~nm}\right.$, dashed line) and PTT as a film on a ZnSe single crystal $\left(\lambda_{\mathrm{em}}=650 \mathrm{~nm}\right.$, dotted line $)$.

bance of the ZnSe single crystal (due to its thickness of ca. $0.5 \mathrm{~mm}$ ), which hampers the recording of reliable excitation spectra.

\section{Conclusion}

From AFM images and the UV-vis absorption and fluorescence spectra of the PTT/ZnSe single crystal composite, it can be concluded that PTT possesses a high affinity for a ZnSe single crystal surface. This also induces electronic contact between these constituents. AFM images also reveal good coverage of the ZnSe single crystal by PBTT. The electronic contact between PBTT and the ZnSe single crystal is, however, difficult to establish because of the severe steric repulsion between the side chains, which leads to a highly distorted backbone. Therefore, the properties do not change upon going from solution to the solid state and when depositing PBTT onto a ZnSe single crystal.

The presence of oxygen-rich oligo(oxyethylene) side chains appears to be paramount for an adhesive contact between polythiophenes and inorganic semiconductor surfaces. Since the oxidation potentials of PTT and ZnSe also compare favorably, PTT/ZnSe composites fulfil a number of conditions to be a suitable hybrid organic/inorganic system for potential application in LEDs. Based on its oxidation potential, PBTT may be even a better candidate for hole injection into $\mathrm{ZnSe}$ but, due to the distorted backbone charge transport in this polymer, is expected to be less facile.

Acknowledgements: We acknowledge the Netherlands Organization for Scientific Research, Priority Program of Materials (NWO-PPM) for financial support of this work and Dr. J. F. Suyver and Prof. Dr. A. Meijerink (Department of Condensed Matter and Interfaces, Utrecht University) for the gift of $\mathrm{ZnSe}$ single crystals. 
[1] J. H. Burroughes, D. D. C. Bradley, A. R. Brown, R. N. Marks, K. Mackay, R. H. Friend, Nature 1990, 347, 539.

[2] H. W. Heuer, R. Wehrmann, S. Kirchmeyer, Adv. Funct. Mater. 2002, 12, 89 .

[3] S.-H. Jin, J.-E. Jung, I.-S. Yeom, S.-B. Moon, K. Koh, S.-H. Kim, Y.-S. Gal, Eur. Polym. J. 2002, 38, 895.

[4] H. Sirringhaus, N. Tessler, R. H. Friend, Science 1998, 280, 1741.

[5] A. van Dijken, J. J. A. M. Bastiaansen, N. M. M. Kiggen, B. M. W. Langeveld, C. Rothe, A. Monkman, I. Bach, P. Stössel, K. Brunner, J. Am. Chem. Soc. 2004, 126, 7718.

[6] R. H. Friend, N. C. Greenham, "Electroluminescence in Conjugated Polymers", in: Handbook of Conducting Polymers, 2nd edition, T. A. Skotheim, R. L. Elsenbaumer, J. R. Reynolds, Eds., Marcel Dekker, Inc., New York 1998, p. 823.

[7] A. Kraft, A. C. Grimsdale, A. B. Holmes, Angew. Chem., Int. Ed. 1998, 37, 402.

[8] Y. Li, G. Vamvounis, S. Holdcroft, Macromolecules 2002, 35,6900

[9] L. Chen, L. S. Roman, D. M. Johansson, M. Svensson, M. R. Andersson, R. A. J. Janssen, O. Inganäs, Adv. Mater. 2000, 15,1110 .

[10] A. Bolognesi, A. Giacometti Schieroni, C. Botta, M. Marinelli, R. Mendichi, R. Rolandi, A. Relini, O. Inganäs, M. Theandher, Synth. Met. 2003, 139, 303.

[11] S. C. Farmer, T. E. Patten, Polym. Prepr. (Am. Chem. Soc., Div. Polym. Chem.) 2001, 42, 578.

[12] A. Shik, S. Yu, E. Johnson, H. Ruda, E. H. Sargent, SolidState Electron. 2002, 46, 61.

[13] K. Yoshino, Y. Kawagishi, S. Tatsuhara, H. Kajii, S. Lee, M. Ozaki, Z. V. Vardeny, A. A. Zakhidov, Superlatt. Microstruct. 1999, 25, 325.

[14] R. D. McCullough, S. P. Williams, J. Am. Chem. Soc. 1993, $115,11608$.

[15] R. D. McCullough, S. P. Williams, Polym. Prepr. (Am. Chem. Soc., Div. Polym. Chem.) 1994, 35, 300.

[16] R. D. McCullough, S. P. Williams, Chem. Mater. 1995, 7, 2001.
[17] R. D. McCullough, S. P. Williams, S. Tristam-Nagle, M. Jayaraman, P. C. Ewbank, L. Miller, Synth. Met. 1995, 69, 279.

[18] G. H. Schoenmakers, Ph.D. Thesis, Utrecht University, Utrecht 1996.

[19] J. Friedrich, M. Baumgarten, Appl. Magn. Reson. 1997, 13, 393.

[20] B. M. W. Langeveld-Voss, R. A. J. Janssen, E. W. Meyer, J. Mol. Struct. 2000, 521, 285.

[21] S.-H. Jin, H.-J. Lee, Y.-K. Sun, H.-D. Kim, K.-N. Koh, Y.-S. Gal, D.-K. Park, Eur. Polym. J. 1999, 35, 89.

[22] B. Raju, I. Okun, F. Stavros, M. F. Chan, Bioorg. Med. Chem. Lett. 1997, 7, 933.

[23] R. D. McCullough, P. C. Ewbank, "Regioregular, Headto-Tail Coupled Poly(3-alkylthiophene) and its Derivatives", in: Handbook of Conducting Polymers, 2nd edition, T. A. Skotheim, R. L. Elsenbaumer, J. R. Reynolds, Eds., Marcel Dekker, Inc., New York 1998, p. 225.

[24] T. Yamamoto, A. Morita, Y. Miyazaki, T. Maruyama, H. Wakayama, Z. Zhou, Y. Nakamura, T. Kanbara, Macromolecules 1992, 25, 1214.

[25] M. Leclerc, G. Daoust, J. Chem. Soc., Chem. Commun. 1990, 273.

[26] L. M. Goldenberg, I. Lévesque, M. Leclerc, M. C. Petty, J. Electroanal. Chem. 1998, 447, 1.

[27] J. F. Suyver, Ph.D. Thesis, Utrecht University, Utrecht 2003.

[28] R. Steiner, M. L. W. Thewalt, R. N. Bhargava, Solid State Commun. 1985, 56, 933.

[29] K. Ogata, T. Kera, D. Kawaguchi, S. Fujita, S. Fujita, J. Cryst. Growth 1997, 170, 507.

[30] J. Z. Zheng, J. W. Allen, D. E. Spence, W. E. Sleat, W. Sibbett, Appl. Phys. Lett. 1993, 62, 63.

[31] M. Theander, A. Yartsev, D. Zigmantas, V. Sundström, W. Mammo, M. R. Andersson, O. Inganäs, Phys. Rev. B 2000, $61,12957$.

[32] N. J. Turro, "Modern Molecular Photochemistry", 2nd edition, Benjamin/Cunnings, Menlo Park 1978. 